\title{
Pseudotumor in Metal-on-metal Total Hip Arthroplasty: An Unusual Complication
}

\author{
1Jagandeep S Virk, ${ }^{2}$ Sudhir K Garg, ${ }^{3}$ Purnima Aggarwal, ${ }^{4}$ Reetu Kundu, ${ }^{5}$ Robin Bohat
}

\begin{abstract}
Second-generation metal-on-metal (MoM) total hip arthroplasty (THA) was introduced to overcome the complications associated with the wear debris from ultrahigh molecular weight polyethylene (UHMWPE). However, a new type of complication began appearing, described as aseptic lymphocyte-dominated vasculitis-associated lesion (ALVAL). Patients with ALVAL complain of pain and, in some cases, extensive swelling around the hip joint known as "pseudotumors." The cause is unknown and probably multifactorial. This may be an adverse reaction to an excess of particulate metal wear debris or a hypersensitivity reaction to a normal amount of metal debris. Surgical findings are typical and symptoms tend to resolve reliably following conversion to an alternative bearing surface. We report one such case of a 55-year-old male, who underwent a revision of bearing surfaces because of ALVAL and pseudotumor formation following an MoM THA at our institute.
\end{abstract}

Keywords: Aseptic lymphocyte-dominated vasculitisassociated lesion, Hip replacement, Hip resurfacing, Metal-onmetal hip arthroplasty, Pseudotumor, Revision.

How to cite this article: Virk JS, Garg SK, Aggarwal P, Kundu R, Bohat R. Pseudotumor in Metal-on-metal Total Hip Arthroplasty: An Unusual Complication. J Postgrad Med Edu Res 2018;52(1):26-30.

\section{Source of support: Nil}

Conflict of interest: None

\section{INTRODUCTION}

Total hip arthroplasty is now an established surgical option to alleviate pain and increase mobility in patients suffering from end-stage primary or secondary arthritis of the hip joint. It is also being done in avascular necrosis (AVN) of the femoral head, which is a more common indication for THA in Indian population as compared

\footnotetext{
1,5Senior Resident, ${ }^{2}$ Professor and Head, ${ }^{3}$ Professor, ${ }^{4}$ Assistant Professor

1,2,5Department of Orthopedics, Government Medical College and Hospital, Chandigarh, India

${ }^{3}$ Department of Radiodiagnosis, Government Medical College and Hospital, Chandigarh, India

${ }^{4}$ Department of Pathology, Government Medical College and Hospital, Chandigarh, India

Corresponding Author: Jagandeep S Virk, Senior Resident Department of Orthopedics, Government Medical College and Hospital, Chandigarh, India, Phone: +919888884149, e-mail: jaganvirk_09@yahoo.co.in
}

with the Caucasian population in whom THA for primary osteoarthritis of hip predominates. According to Frost and Sullivan's research, almost 70,000 joint replacement surgeries were performed in India in the year 2011. The demand for joint replacement surgery is set to increase further. ${ }^{1}$

McKee and Watson-Farrar ${ }^{2}$ introduced the MoM artificial hip joint between 1956 and 1960, and used it in 40 patients with hip disability. They reported $51 \%$ goodto-fair clinical results. The system was cementless on both the acetabular and femoral sides. Charnley ${ }^{3}$ subsequently promoted cemented THA based on the concept of low friction arthroplasty by making use of bone cement for fixation, adoption of a 22.2-mm femoral head, and UHMWPE acetabular cup. Wroblewski et al ${ }^{4}$ reported mean survival rates of $84.7 \%$ at 15 years after surgery in cases where original Charnley-cemented THA was used. However, the outcomes of other cemented THA procedures were very poor: Loosening occurred in $34 \%$ at 7.4 years after surgery using the Charnley-Müller type, and $40 \%$ at 10 years after surgery using the Müller-type prosthesis. ${ }^{5,6}$ These poor outcomes of early cemented THAs were due to the implant design and cementing technique in many cases. However, at that time, cement was considered to be the cause and loosening was called "cement disease."

To circumvent the "cement disease," there was a shift toward uncemented THA with femoral and acetabular components using MOM bearing surfaces. ${ }^{7}$ These firstgeneration MoM prostheses were ultimately taken out of use due to numerous reports of metallosis and patients suffering from a variety of medical conditions due to high levels of metal ions in their blood serum and body tissues. Mechanism of MoM failure was frictional torque leading to subsequent corrosion of the bearing surfaces. ${ }^{8-11}$ Firstgeneration MoM prostheses were abandoned in favor of bearing surfaces that included polyethylene and ceramic components on the acetabular side. Although ceramicon-ceramic components have excellent survivorship and have obtained positive results in various studies, it was not without its own problems, such as ceramic fracture, squeaking, and associated osteolysis requiring subsequent revisions in some cases. ${ }^{12,13}$

Improvements in bearing-surface manufacturing and composition resulted in a second generation of MoM implants with improved wear properties, which 
are highly desirable for young and active patients in whom the prosthetics was expected to have greater longevity. ${ }^{10,11}$ It also opened up the opportunity to use larger-sized head in an MoM prosthesis. ${ }^{14-17}$ Early reports suggested high patient satisfaction, low rates of dislocation and wear, and good survival at mediumterm follow-up. ${ }^{18}$ Subsequently reports of the formation of periarticular masses in some patients, referred to as pseudotumors, started appearing. It is also described as ALVAL. The term is currently used to denote a periarticular mass caused by an immunological delayed hypersensitivity response to metal particles, characterized by a lymphocyte-dominated histological pattern. ${ }^{19} \mathrm{~A}$ more specific and broader term used is adverse reaction to metal debris. ${ }^{20}$ The clinical picture may vary from an unexplained discomfort in the hip region, sometimes accompanied by clicking or subluxation. ${ }^{21}$ Occasionally on examination, a swelling in the buttock region or proximal thigh or a lump in the inguinal region can be found. Imaging studies, such as magnetic resonance imaging (MRI) help in making a diagnosis and planning of surgery. When the diagnosis of pseudotumor is established and symptoms are troublesome, ${ }^{22}$ revision surgery is an option. The mass is removed as radically as safely possible and the bearing surfaces are revised.

\section{CASE REPORT}

In January 2017, a 55-year-old man was admitted to our institute with complaints of occasional left-sided posterolateral thigh and hip discomfort with swelling in his gluteal and trochanteric region for the past 3 to 4 months. The swelling was ill-defined and cystic in nature with no signs of inflammation. He had undergone successful uncemented THA in May 2009 for AVN of the left femoral head in which large-diameter femoral head MoM prosthesis was used. The acetabular cup and

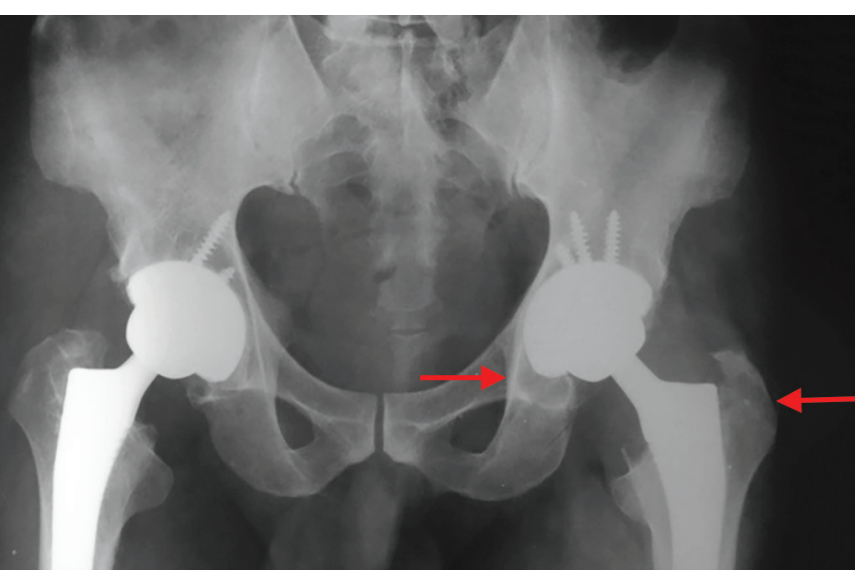

Fig. 1: X-ray showing areas of lysis (red arrows) in the inferior aspect of acetabulum and in the proximal femoral and trochanteric region metal insert were of $56 \mathrm{~mm}$ size and femoral head of $36 \mathrm{~mm}$ (DePuy Synthes PINNACLE® Hip Solutions). The contralateral hip also with AVN of the femoral head was replaced with a similar prosthesis after 2 months of the first replacement and since then, he has remained symptom-free until date.

Fresh radiographs of the affected hip and pelvis with both hips were carried out that revealed osteolysis in inferior aspect of acetabulum, ischium, and proximal femoral and trochanteric region (Fig. 1).

A retrospective analysis of his radiographs revealed that until 6 years of his follow-up, the prosthesis appeared secure with no signs of loosening or zones of osteolysis (Fig. 2).

As there was no history of fever or local signs of inflammation apart from swelling to suggest infection, a provisional diagnosis of ALVAL and pseudotumor was made, based on its not-so-rare occurrence in previous studies in literature on MoM THAs. ${ }^{23}$

Further imaging investigations were done in order to confirm our provisional diagnosis. The MRI of the pelvis with both hip joints (Figs 3 and 4) demonstrated a soft tissue lesion in the left periarticular region extending into thigh posteriorly. The size of the lesion was reported as $95 \times 57 \mathrm{~mm}$ with edema in the posteromedial regions of the hip and also in the gluteal muscles. The likely differential was provided as pseudotumor after clinical correlation. Routine blood investigations including cell counts, erythrocyte sedimentation rate, and quantitative C-reactive protein were normal.

Patient was planned for revision of the bearing surfaces according to the recent guidelines for patient management with MoM arthroplasty-related adverse reactions. ${ }^{24}$ In the operating room, after induction of general anesthesia, the patient was placed in lateral position and the previous incision of the posterolateral

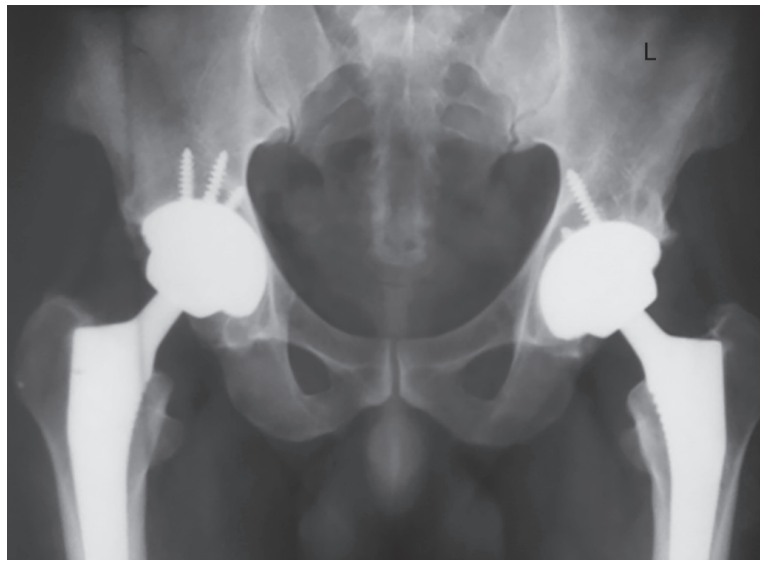

Fig. 2: X-ray of pelvis with both hips showing well-fixed implants (left side) at 6 years follow-up 


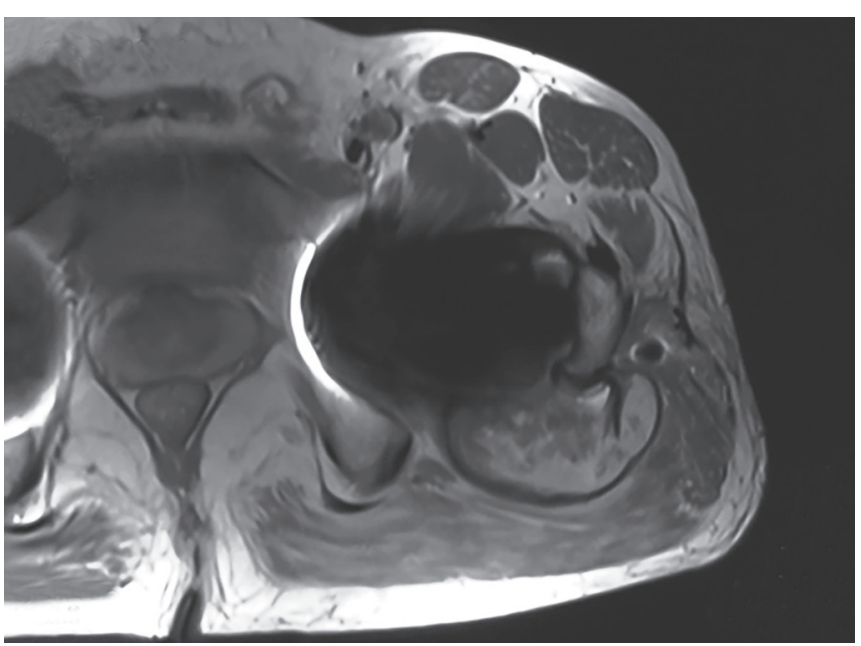

Fig. 3: Axial section MRI of the affected hip showing a mass in the gluteal region (red arrow)

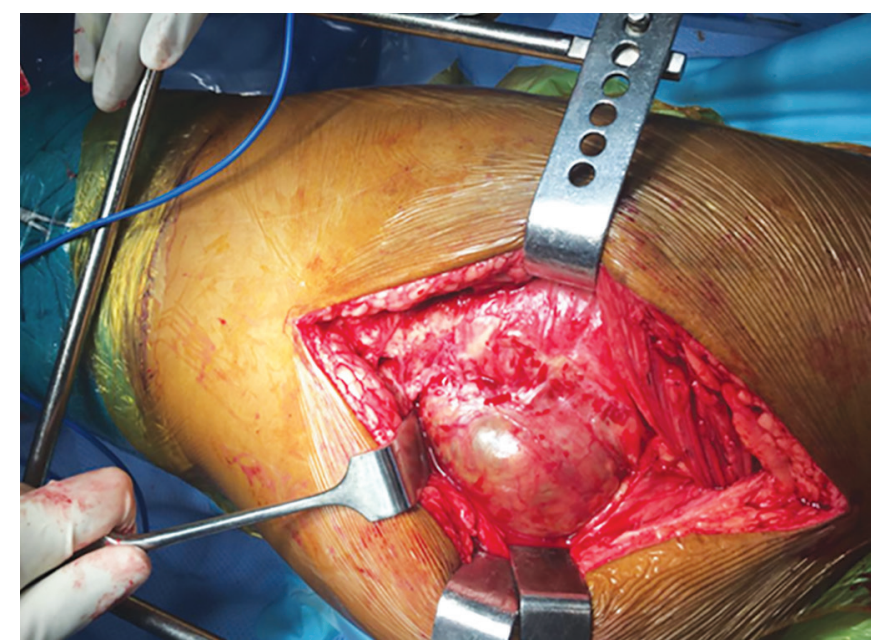

Fig. 5: Abnormal soft tissue mass (pseudotumor) seen in the gluteal region intraoperatively on exposing the hip

exposure to hip joint was utilized. The abductors were found to be normal and partial engulfment of the short external rotators by the mass was seen. The abnormal mass-like tissue was excised as much as possible (Figs 5 and 6) and sent for complete histopathological evaluation. During the revision procedure, the patient's acetabular and femoral components were found to be well fixed. No evidence of corrosion was noted in the femoral head and at the neck taper of the femoral component. The revision was to a ceramic-on-polyethylene articulation with a highly cross-linked polyethylene acetabular liner and a ceramic femoral head. The insert used was of standard $56 \mathrm{~mm}$ size and femoral head of $36+8.5 \mathrm{~mm}$ (DePuy Synthes) size was found suitable.

Postoperatively, patient was made to stand and walk with help of a walker on the next day of the surgery. Appropriate physiotherapy exercises were initiated and monitored. Hip precautions were explained. The patient was relieved of the groin and thigh pain, which

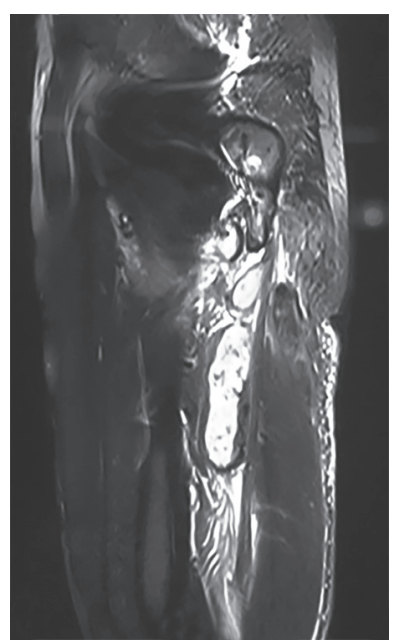

Fig. 4: Sagittal section MRI showing the longitudinal extent of the soft tissue mass

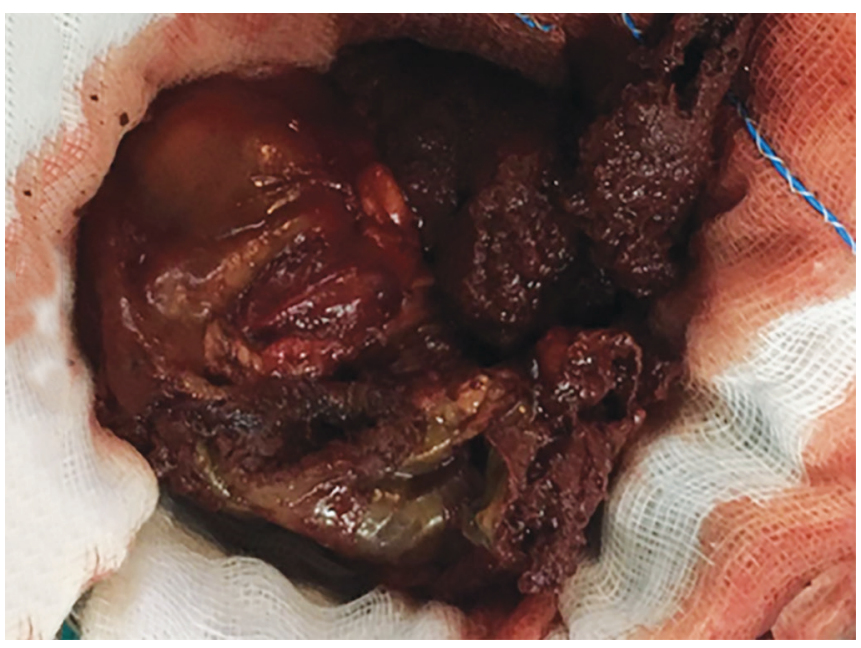

Fig. 6: Resected pseudotumor

he had felt earlier before undergoing the revision surgery. Patient was discharged at stitch removal on 12th day after surgery.

The histopathological report confirmed our provisional diagnosis. The microscopic findings (Fig. 7) showed multiple soft tissue pieces lined by hyperplastic synovial lining, largely covered with necrotic fibrinous exudates. The underlying fibrous tissue showed presence of sheets of macrophages along with lymphocytes and congested blood vessels along with few histiocytic giant cells. The final impression was consistent with a diagnosis of ALVAL.

\section{DISCUSSION}

Second-generation MoM prosthesis was introduced for its advantages over conventional articulations, such as low rates of wear and increased stability due to larger head size. ${ }^{25}$ The use of this prosthesis had become increasingly popular during the last decade, especially 


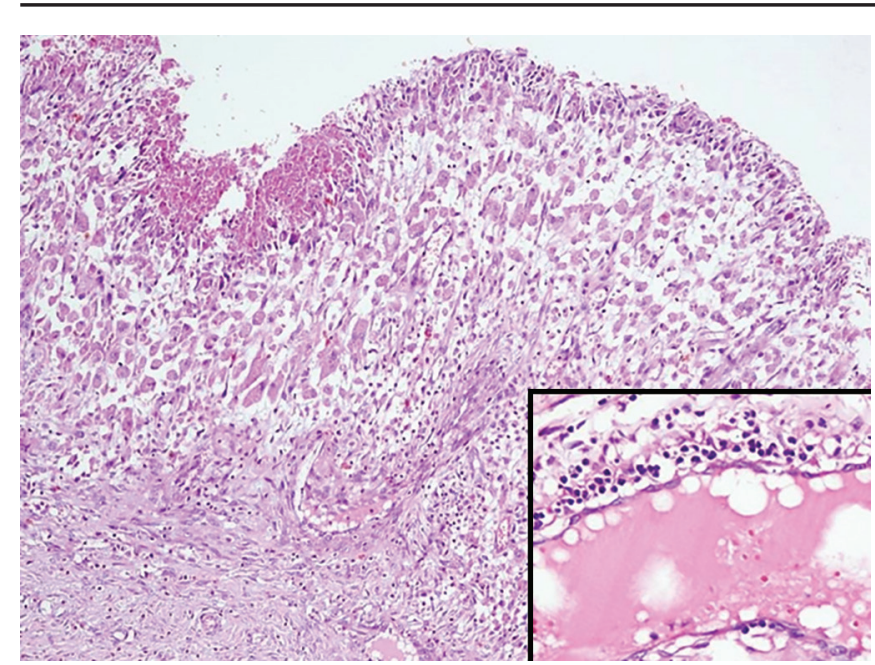

Fig. 7: Section showing hyperplastic synovium and fibrinous exudate on surface beneath which plenty of histiocytes, lymphocytes, congested blood vessels, and few fibroblasts are seen (H\&E, 100×). Inset shows numerous lymphocytes in the vessel wall (H\&E, 400x). H\&E: Hematoxylin and eosin

in young, mobile patients. ${ }^{26}$ However, there have been several reports of high incidence of ALVAL and pseudotumor formation in patients who underwent MoM THAs and, more recently, in patients undergoing MoM hip resurfacings. ${ }^{23,27}$

The possible mechanism behind ALVAL in MoM THAs is the slow release of metal ions from the prosthetic-bearing surfaces as a by-product of normal wear. These metal ions are present in adjacent periprosthetic soft tissue. These wear particles elicit a type IV response in the local tissue. This local destructive response can lead to pain, osteolysis, loosening of the prosthetic components, and formation of soft tissue mass. Though overall wear rate and size of the wear particles from the second-generation implants are smaller than those associated with the first-generation MoM prostheses or from conventional metal-on-polyethylene components, it is postulated that the smaller size and higher surface area of MoM debris particles actually facilitate their diffusion into surrounding tissues and local tissue reaction resulting in the formation of pseudotumors. ${ }^{28}$

Symptoms emerge slowly and, initially, are mild and often have little impact on patient's activities. When symptoms of swelling, pain in the groin, and clicking become sufficient to warrant revision, a sizeable pseudotumor with extensive local-tissue destruction may already be present. A high index of suspicion of ALVAL is also warranted in cases presenting with symptoms even after a very long time of the primary surgery of MoM THA. In our case, patient developed symptoms almost 7 years following his replacement surgery. A search of literature reveals that pseudotumors have been reported to become symptomatic up to 15 years postoperatively. ${ }^{29}$ More serious symptoms include dislocation, nerve palsy, ${ }^{30}$ and fracture, ${ }^{29}$ depending on the location and size of the pseudotumor.

Due to these possible complications, regular followup and a high index of suspicion for a metal-related adverse reaction are very important. Imaging modalities like ultrasound and computed tomography scan provide some information, but it is the metal artifact reduction scanning $\mathrm{MRI}^{31}$ that helps in confirming a diagnosis. The ALVAL is confirmed by histopathology of the biopsy specimen.

Since a large number of patients, especially in the younger age group, underwent hip arthroplasty with MoM-bearing surfaces, one can anticipate an increased number of patients presenting with ALVAL and undergoing subsequent revisions for prosthetic failure. Accurate assessment is crucial because an intraoperative diagnosis of chronic inflammation suggestive of ALVAL will necessitate a replacement of the prosthetic component-bearing surfaces. Also, the importance of intervening early cannot be understated. Late intervention in such cases when gross osteolysis and loosening has already occurred with an unstable prosthesis and inadequate bone stock can lead to a difficult revision surgery.

\section{REFERENCES}

1. Available from: www.researchandmarkets.com/reports/ 1877536/overview of orthopedic joint replacement market.pdf.

2. McKee GK, Watson-Farrar J. Replacement of arthritic hips by the McKee-Farrar prosthesis. J Bone Joint Surg Br 1966 May;48(2):245-259.

3. Charnley J. Arthroplasty of the hip: a new operation. Lancet 1961 May 27;1(7187):1129-1132.

4. Wroblewski BM, Siney PD, Fleming PA. Charnley lowfrictional torque arthroplasty in patients under the age of 51 years: follow-up to 33 years. J Bone Joint Surg Br 2002 May;84(4):540-543.

5. Olsson SS, Jernberger A, Tryggö D. Clinical and radiological long-term results after Charnley-Müller total hip replacement: a 5 to 10 year follow-up study with special reference to aseptic loosening. Acta Orthop Scand 1981 Oct;52(5):531-542.

6. Sutherland CJ, Wilde AH, Borden LS, Marks KE. A ten-year follow-up of one hundred consecutive Müller curved-stem total hip-replacement arthroplasties. J Bone Joint Surg Am 1982 Sep;64(7):970-982.

7. Amstutz HC, Grigoris P. Metal on metal bearings in hip arthroplasty. Clin Orthop Relat Res 1996 Aug;(329 Suppl):S11-S34.

8. Evans EM, Freeman MA, Miller AJ, Vernon-Roberts B. Metal sensitivity as a cause of bone necrosis and loosening of the prosthesis in total joint replacement. J Bone Joint Surg Br 1974 Nov;56-B(4):626-642.

9. Higuchi F, Inoue A, Semlitsch M. Metal-on-metal CoCrMo McKee-Farrar total hip arthroplasty: characteristics of a long term follow up study. Arch Orthop Trauma Surg 1997;116(3): 121-124.

10. Howie DW, Vernon-Roberts B. The synovial response to intraarticular cobalt-chrome wear particles. Clin Orthop Relat Res 1988 Jul;(232):244-254. 
11. Huo MH, Salvati EA, Lieberman JR, Betts F, Bansal M. Metallic debris in femoral osteolysis in failed cemented total hip arthroplasties. Clin Orthop Relat Res 1992 Mar;(276):157-168.

12. Chana R, Facek M, Tilley S, Walter WK, Zicat B, Walter WL. Ceramic-on-ceramic bearings in young patients: outcomes and activity levels at minimum ten-year follow-up. Bone Joint J 2013 Dec;95-B(12):1603-1609.

13. Owen DH, Russell NC, Smith PN, Walter WL. An estimation of the incidence of squeaking and revision surgery for squeaking in ceramic-on-ceramic total hip replacement: a meta-analysis and report from the Australian Orthopaedic Association National Joint Registry. Bone Joint J 2014 Feb;96-B(2):181-187.

14. Wagner M, Wagner $\mathrm{H}$. Medium term results of a modern metal-on-metal system in total hip replacement. Clin Orthop Relat Res 2000 Oct;(379):123-133.

15. Dorr LD, Wan Z, Longjohn DB, Dubois B, Murken R. Total hip arthroplasty with use of the Metasul metal-on-metal articulation: four to seven-year results. J Bone Joint Surg Am 2000 Jun;82(6):789-798.

16. Milosev I, Trebse R, Kovac S, Cör A, Pisot V. Survivorship and retrieval analysis of Sikomet metal-on-metal total hip replacements at a mean of seven years. J Bone Joint Surg Am 2006 Jun;88(6):1173-1182.

17. Sieber HP, Rieker CB, Kottig P. Analysis of 118 second generation metal-on-metal retrieved hip implants. J Bone Joint Surg Br 1999 Jan;81(1):46-50.

18. Haddad FS, Thakrar RR, Hart AJ, Skinner JA, Nargol AV, Nolan JF, Gill HS, Murray DW, Blom AW, Case CP. Metal-onmetal bearings: the evidence so far. J Bone Joint Surg Br 2011 May;93(5):572-579.

19. Watters TS, Eward WC, Hallows RK, Dodd LG, Wellman SS, Bolognesi MP. Pseudotumor with superimposed periprosthetic infection following metal-on-metal total hip arthroplasty: a case report. J Bone Joint Surg Am 2010 Jul 7;92(7):1666-1669.

20. Langton DJ, Joyce TJ, Jameson SS, Lord J, Van Orsouw M, Holland JP, Nargol AV, De Smet KA. Adverse reaction to metal debris following hip resurfacing: the influence of component type, orientation and volumetric wear. J Bone Joint Surg Br 2011 Feb;93(2):164-171.

21. Maurer-Ertl W, Friesenbichler J, Liegl-Atzwanger B, Kuerzl G, Windhager R, Leithner A. Noninflammatory pseudotumor simulating venous thrombosis after metal-on-metal hip resurfacing. Orthopedics 2011 Oct 5;34(10):e678-e681.
22. Davda K, Lali FV, Sampson B, Skinner JA, Hart AJ. An analysis of metal ion levels in the joint fluid of symptomatic patients with metal-on-metal hip replacements. J Bone Joint Surg Br 2011 Jun;93(6):738-745.

23. Bosker BH, Ettema HB, Boomsma MF, Kollen BJ, Maas M, Verheyen CC. High incidence of pseudotumour formation after large-diameter metal-on-metal total hip replacement: a prospective cohort study. J Bone Joint Surg Br 2012 Jun;94(6):755-761.

24. Drummond J, Tran P, Fary C. Metal-on-metal hip arthroplasty: a review of adverse reactions and patient management. J Funct Biomater 2015 Jun 26;6(3):486-499.

25. Girard J, Bocquet D, Autissier G, Fouilleron N, Fron D, Migaud H. Metal-on-metal hip arthroplasty in patients thirty years of age or younger. J Bone Joint Surg Am 2010 Oct 20;92(14): 2419-2426.

26. SkinnerJ, Gregg P,Kay P,Porter M, Tucker K, RazakK, CrosbieA, Ludgate S. Medicines and Healthcare products Regulatory Agency: report of the expert advisory group lookingat soft tissue reactions associated with metal-on-metal hip replacements, 2010. Available from: http://www.scribd.com/doc/ 61342105/MoM-Final-Report-26-10-2010 (date last accessed 20 February 2012).

27. PanditH,Glyn-JonesS, McLardy-SmithP, GundleR, WhitwellD, Gibbons CL, Ostlere S, Athanasou N, Gill HS, Murray DW. Pseudotumours associated with metal-on-metal hip resurfacings. J Bone Joint Surg Br 2008 Jul;90(7):847-851.

28. Watters TS, Cardona DM, Menon KS, Vinson EN, Bolognesi MP, Dodd LG. Aseptic lymphocyte-dominated vasculitisassociated lesion: a clinicopathologic review of an underrecognized cause of prosthetic failure. Am J Clin Pathol 2010 Dec;134(6):886-893.

29. Griffiths HJ, Burke J, Bonfiglio TA. Granulomatous pseudotumors in total joint replacement. Skeletal Radiol 1987;16(2): 146-152.

30. Clayton RA, Beggs I, Salter DM, Grant MH, Patton JT, Porter DE. Inflammatory pseudotumor associated with femoral nerve palsy following metal-on-metal resurfacing of the hip: a case report. J Bone Joint Surg Am 2008 Sep;90(9): 1988-1993.

31. Anderson H, Toms AP, Cahir JG, Goodwin RW, Wimhurst J, Nolan JF. Grading the severity of soft tissue changes associated with metal-on-metal hip replacements: reliability of an MR grading system. Skeletal Radiol 2011 Mar;40(3):303-307. 